\title{
Cervical Disorder
}

National Cancer Institute

\section{Source}

National Cancer Institute. Cervical Disorder. NCI Thesaurus. Code C40241.

A non-neoplastic or neoplastic disorder that affects the cervix. Representative examples include cervicitis, endocervical polyp, and carcinoma. 